\title{
Water vapor conversion factor over Qinghai-Tibet plateau region considering elevation, latitude and fine seasonal variation is constructed
}

Hua Peng ${ }^{1,2}$, Liangke Huang ${ }^{1,2,3^{*}}$, Chen $\mathrm{Li}^{1,2}{ }^{1,}$ Lilong Liu ${ }^{1,2}$, Sen Wang ${ }^{1,2}$, Shu Wang ${ }^{1,2}$

1. College of Geomatics and Geoinformation, Guilin University of Technology, Guilin 541004, China

2. Guangxi Key Laboratory of Spatial Information and Geomatics, Guilin 541004, China

3. GNSS Research Center, Wuhan Universtiy, Wuhan 430079, China

KEY WORDS: QTm model, Conversion factor, GGOS atmosphere data, GPS Precipitable Water Vapor, weighted mean temperature, water vapor

\begin{abstract}
In this paper, the conversion factor K model of Qinghai-Tibet plateau region was established based on the QTm model which is established using high-precision the Global Geodetic Observing System (GGOS) Atmosphere grid data from 2007 to 2014 . The model took into account the influence of elevation fluctuation and latitude change on the model, and analyzed the relevant characteristics with seasonal changes. The 2015 GGOS grid data and radiosonde data were used as the reference value for accuracy assess. The established QTm model was compared with GPT2w model in bias and RMS. Compared with GGOS grid data, the average annual bias and RMS of QTm model were $-0.28 \mathrm{~K}$ and $2.70 \mathrm{k}$ respectively. The RMS of GPT2w-5 and GPT2w-1 were $58.16 \%$ and $28.84 \%$ higher, respectively. Compared with radiosonde data, QTm model has $1.13 \mathrm{k}$ average annual bias and the RMS error of 2.92k. Compared with GPT2w-5 and GPT2w-1, the RMS value of QTm model was improved by $25.08 \%$ and $29.43 \%$, respectively. The value of atmospheric water vapor conversion coefficient was calculated by the integral method calculated by radio sounding data in the Qinghai-Tibet region in 2015 was used as the reference value for assess the performance of conversion factor $\mathrm{K}$, and compared and analyzed the conversion coefficient $\mathrm{K}$ which provided by QTm and GPT2w. The results show that the value of Tm provided by QTm model has the highest accuracy, which is $25.07 \%$ higher than that of GPT2w-5 and $29.42 \%$ higher than that of GPT2w-1. QTm models can achieve GPS-PWV retrieval precision of better than $2 \mathrm{~mm}$. Which has potential application for high-precision real-time GNSS-PWV retrieving in Qinghai-Tibet region.
\end{abstract}

\section{INTRODUCTION}

Water vapor is the most active gas component on the earth's surface ( He et al.; Yao et al., 2012,2014) . Although it is small in content, its distribution is complex, and its space-time movement affects weather and climate changes. It plays a key role in precipitation, energy transfer and the generation of severe weather conditions. Scientists have been concerned about the long-term variation of global and regional climates. Monitoring changes in atmospheric water vapor is not only important for the detection of atmospheric water vapor, but also better understands the impact of water vapor on global warming. Therefore, Studying water vapor is of great significance. Compared with the traditional methods of detecting water vapor, the ground-based GNSS meteorology has become a hot spot in current research by providing water vapor information with all-weather and high spatial and temporal resolution.

ZWD and PWV have the following conversion relationship (Bevis et al. 1994):

$$
\begin{aligned}
& \mathrm{PWV}=\mathrm{K} \cdot \mathrm{ZWD} \\
& \Pi=\frac{10^{6}}{\rho_{w} R_{v}\left(\frac{k_{3}}{T_{m}}+k_{2}^{\prime}\right)}
\end{aligned}
$$

Where $\mathrm{K}$ indicates the conversion factor and Tm denote the weighted average temperature; $R_{v}=461.495 \mathrm{~J} /(\mathrm{kg} \cdot \mathrm{K})$, is the specific gas constant; $\rho_{w}$ is the density of water; $k_{2}^{\prime}=22.1$ $\mathrm{K} / \mathrm{hPa} ; \mathrm{k}_{3}=3.739 \cdot 10^{5} \mathrm{~K}^{2} / \mathrm{hPa}$. (Davis et al. 1985 ; Bevis et al. 1994) The first-order reciprocal of the weighted average temperature is as follows:

$$
\frac{\mathrm{dK}}{\mathrm{dT}}=\frac{10_{\mathrm{m}}^{6}}{\rho_{\mathrm{wR}_{\mathrm{v}}}} \cdot \frac{\mathrm{k}_{3}}{\left(\mathrm{k}_{2}^{\prime}+\mathrm{k}_{3} / \mathrm{T}_{\mathrm{m})}{ }^{2} \mathrm{~T}_{\mathrm{m}}^{2}\right.}
$$

\footnotetext{
* Corresponding author
} 
It can be seen from the Eq. (1) and (2) that the conversion coefficient $\mathrm{K}$ is the key to calculating the PWV, and the conversion coefficient can be calculated by the weighted average temperature Tm. From Eq. (3) the error of the atmospheric conversion coefficient $\mathrm{K}$ caused by the weighted temperature is much smaller than that caused by the ground pressure (Jiang, 2014). Higher precision K values can be obtained by integration using radiosonde data and atmospheric reanalysis data, but the $\mathrm{K}$ value at any position cannot be obtained by calculation. In order to obtain higher precision water vapor information, accurate $\mathrm{K}$ value calculation is extremely important, and many scholars have also established many K-value models for non-meteorological parameters. Emardson et al. (2000) establish a K-value model for North America using radiosonde data. Yao et al. (2016) establish a K-value model of global empirical conversion factor without site meteorological parameters. Later, many scholars refined the K-value model established by Emardson without meteorological parameters and obtained good experimental results (Qu et al. 2002; Yao et al.2015, Huang et al. 2019). These models are easy to use but sacrifice their accuracy (Yao et al.2014).

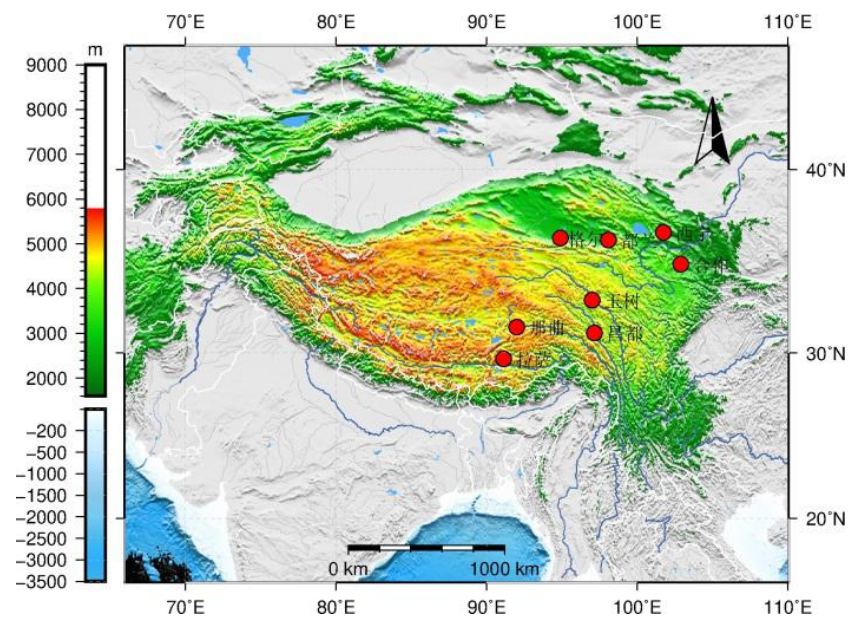

Figure1. Distribution of the radiosonde stations in Qinghai-Tibet Area

The Qinghai-Tibet Plateau has complex terrain and varied climate. As one of the most sensitive regions in the world, it has become a hotspot for many scholars (Wang et al.2014; $\mathrm{Wu}$ et al.2014;Zhang et al.2013). However, the Qinghai-Tibet area has a high altitude, the radiosonde stations are sparse and unevenly distributed, and it is difficult to obtain accurate water vapor information due to the limitation of corresponding technical conditions. With the continuous improvement of analytical data, the continuous development of GNSS meteorology makes it possible to provide accurate and reliable $\mathrm{k}$ values. In ground-based GPS meteorology, conversion factor $\mathrm{K}$ is an important parameter for calculating PWV.In order to obtain higher-precision water vapor information, this paper uses the GGOS data of 2007-2014 to establish the Tm model of Qinghai-Tibet area, referred to as QTm, to calculate the atmospheric conversion coefficient and Comparison the $\mathrm{K}$ value calculated by GPT2w-5 and GPT2w-1.

\subsection{Establish a Tm model}

The study area selected in this paper is $25^{\circ}-40^{\circ} \mathrm{N}, 70^{\circ}-105^{\circ} \mathrm{E}$, and the selection of the range of the Qinghai-Tibet Plateau by reference to Bai et al(2018). Considering that the atmospheric weighted average temperature $\mathrm{Tm}$ and the conversion coefficient $\mathrm{K}$ are both affected by the height factor ((Xiao et al.2014; Yu et al.2014) and the latitude is also related. Therefore, the influence of latitude and altitude on the accuracy of the model is considered when establishing the Tm model. The terrain of the Qinghai-Tibet plateau is highly undulate, which will greatly limit the high-precision real-time application of Global Navigation Satellite System (GNSS) meteorology in the Qinghai-Tibet plateau. Our aim is to create a model for the conversion of the zenith wet delay to the Precipitable Water Vapor (PWV). The establishment of the Tm model is crucial.

$$
\begin{aligned}
\text { QTm }=a_{0}+a_{1} h+ & a_{2} \text { lat }+a_{3} \cos \left(2 \pi \frac{d o y}{365.25}\right) \\
& +a_{4} \sin \left(2 \pi \frac{d o y}{365.25}\right)+\cos \left(4 \pi \frac{d o y}{365.25}\right) \\
& +a_{6} \sin \left(4 \pi \frac{d o y}{365.25}\right)
\end{aligned}
$$

\subsection{Model accuracy analysis}

\begin{tabular}{|c|c|c|c|}
\hline Sitename & Longitude & Latitude & Height \\
\hline Golmud & 94.9 & 36.41 & 2809 \\
Dulan & 98.1 & 36.3 & 3192 \\
Xining & 101.8 & 36.71 & 2296 \\
Nagqu & 92 & 31.48 & 4508 \\
Lhasa & 91.13 & 29.66 & 3650 \\
Yushu & 97.01 & 33.01 & 3682 \\
Hezuo & 102.9 & 35 & 2910 \\
Qamdo & 97.16 & 31.15 & 3307 \\
\hline
\end{tabular}


Table1. Radiosonde stations location information

Use the 2015 GGOS grid Tm data and radiosonde data to verify the accuracy of the QTm, GPT2w-5 and GPT2w-1 models. Its accuracy is shown in Figure 2 and Figure 3. The established QTm model was compared with GPT2w model in bias and RMS. Compared with GGOS grid data, the average annual bias and RMS of QTm model were $-0.28 \mathrm{~K}$.

\begin{tabular}{|c|c|c|c|c|}
\hline & Model & GPT2w-5 & GPT2w-1 & QTm \\
\hline \multirow{3}{*}{ Grid } & Bias (K) & 2.03 & 1.87 & -0.28 \\
& RMS (K) & 6.44 & 3.79 & 2.70 \\
& Bias (K) & -2.39 & -2.67 & 1.13 \\
& RMS (K) & 3.90 & 4.14 & 2.92 \\
\hline
\end{tabular}

Table 2 model accuracy comparison
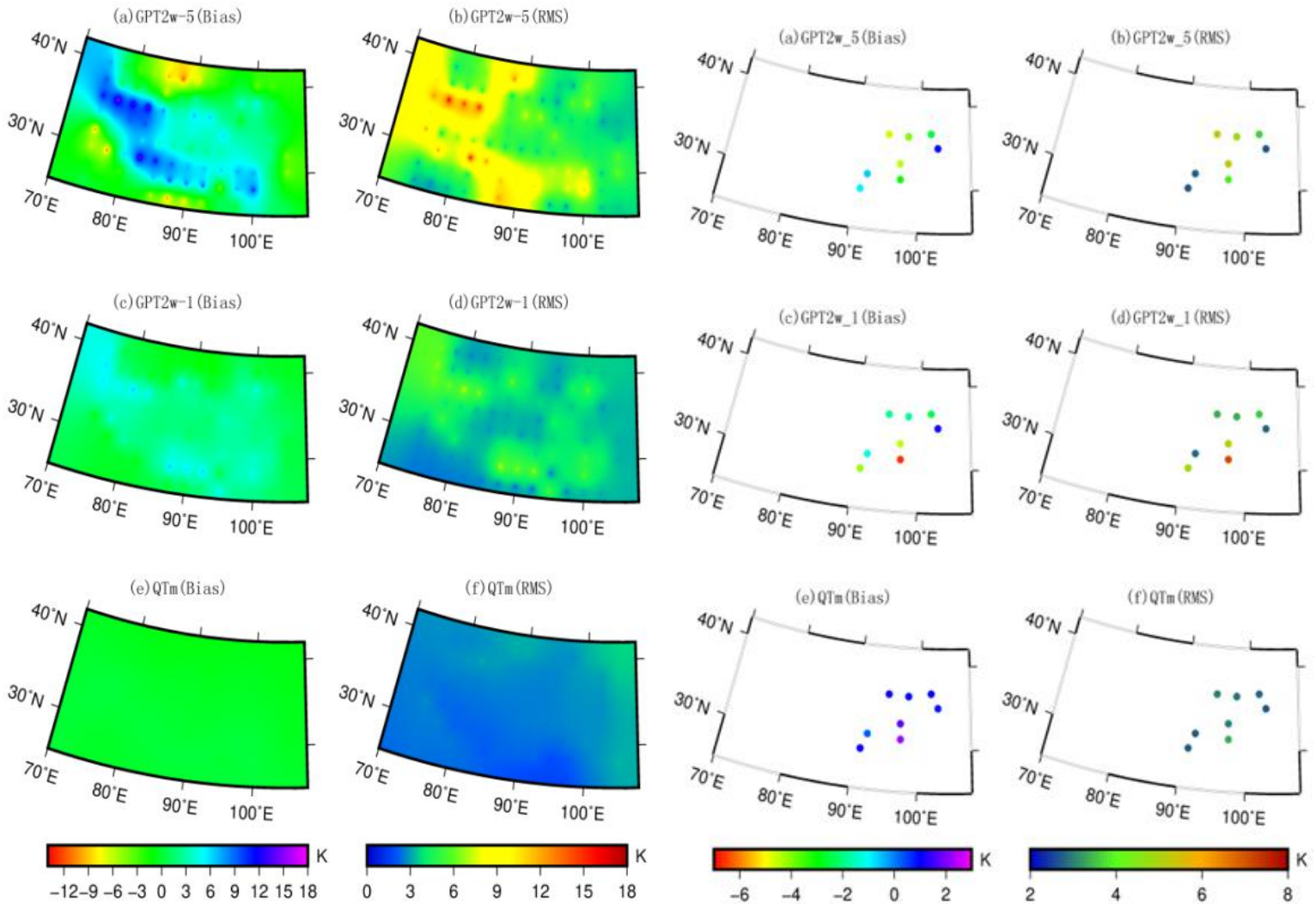

Figure2. The bias and RMS of the three models relative to the 2015 GGOS grid date

As can be seen from Figure 2, GPT2w-5 has the largest bias and RMS; QTm shows better accuracy and stability, probably because QTm considers the influence of height on the model. Since GPT2w-1 has a higher model resolution than GPT2w-5, this also explains that GPT2w-1 has better accuracy thanGPT2w-5 on the Tibetan Plateau.

This will be beneficial to obtain a higher precision $\mathrm{K}$ value when calculating the atmospheric conversion coefficient using Eq. (2). This created conditions for inverting high-precision GPS-PWV.

\section{CONVERSION FACTOR}

\subsection{Conversion factor obtained by model}

From the Eq. (2), we can get the $\mathrm{K}$ value of the 
Qinghai-Tibet area. In order to analyze the influencing factors of the conversion factor, the article analyzes the relevant aspects from three aspects: annual cycle, latitude and altitude. In order to explain the influence of the annual cycle on the conversion factor, the Tm value of Lhasa in 2015-2018 was obtained by QTm model, and then converted into $\mathrm{K}$ value.

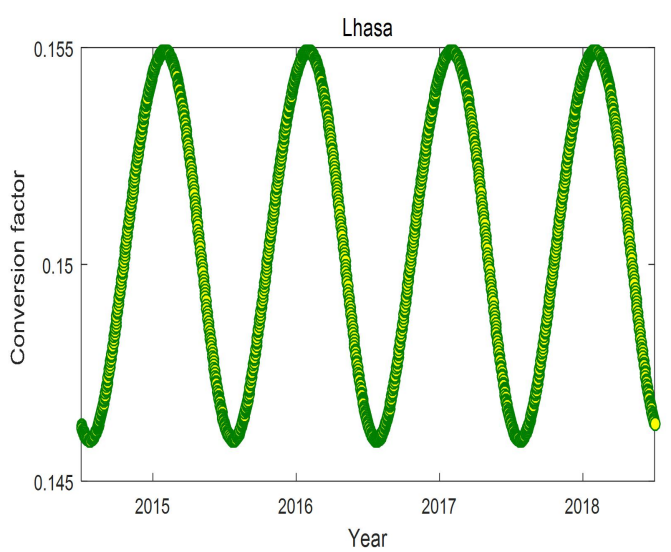

Figure3. The conversion factor varies with annual cycle

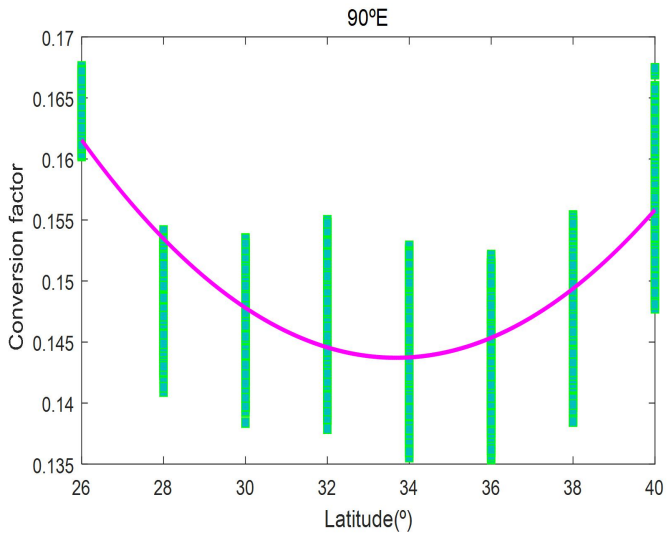

Figure4. The conversion factor varies with latitude

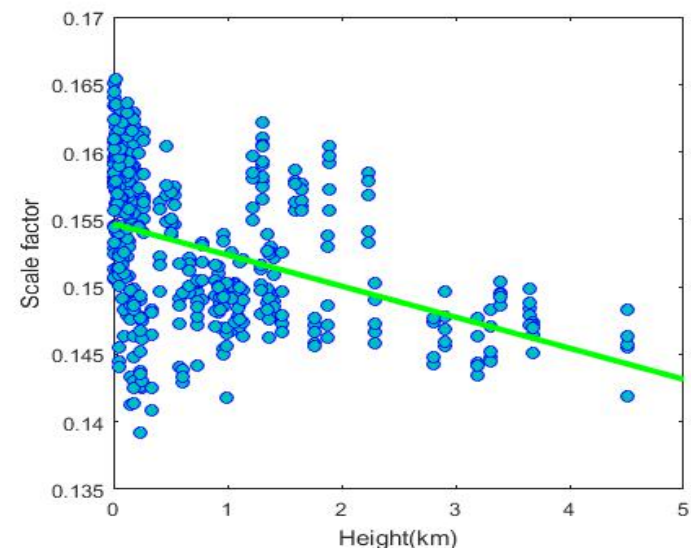

Figure5. The conversion factor varies with height

The fitting results are shown in Figure 3. Figures 4 and 5 illustrate the change in conversion factor with latitude and altitude. In Figure 3, it can be seen that the conversion factor has a significant annual cycle change. The effects of latitude and elevation on conversion factors can be seen from Figure 4 and Figure 5.

In order to explain the influence of latitude on $\mathrm{K}$, the selected longitude is 90 and the latitude interval is 2 degrees for analysis. In order to investigate whether the conversion factor is related to the elevation, the data of the whole year of 2015 is used for statistical analysis to analyze the change of the conversion factor with the elevation. Figure 5 shows the variation of the conversion factor with the elevation. It can be seen from the figure that the conversion factor changes significantly with the change of elevation and exhibits an approximate linear relationship.

In order to evaluate the accuracy of the converted $\mathrm{K}$ value, using the radiosonde data of 2015 , the $\mathrm{K}$ value obtained by the integration algorithm is used as a reference value to evaluation the accuracy of the model.

\subsection{Compared with the integral method}

In order to evaluate the accuracy of the calculated $\mathrm{K}$ value, the $\mathrm{k}$ values calculated by GPT2w-5, GPT2w-1, and QTm are compared with the $\mathrm{K}$ values obtained by the integration method, and the error distribution is shown in Table 2 and Figure 6. It can be seen from Table 2 that the $\mathrm{K}$ value calculated from QTm shows the smallest bias and RMS, 0.0006 and 0.0016 respectively, which is $25.07 \%$ higher than that of GPT2w-5 and $29.42 \%$ higher than that of GPT2w-1. It indicates that the $\mathrm{K}$ value obtained has high accuracy and stability. Among them, GPT2w model shows obvious negative Bias, and GPT2w-1 is more obviously negative Bias than GPT2w-5, which may be caused by grid distribution, leading to large Bias in interpolation algorithm. It can be seen from Fig. 6 that the three models of the Nagqu station have the best consistency with the sounding data.

\begin{tabular}{|c|c|c|c|c|}
\hline \multicolumn{2}{|c|}{ Model } & $\mathrm{K}(\mathrm{GPT} 2 \mathrm{w}-5)$ & $\mathrm{K}(\mathrm{GPT} 2 \mathrm{w}-1)$ & $\mathrm{K}(\mathrm{QTm})$ \\
\hline Bias & Max. & 0.0005 & 0.0007 & 0.0013 \\
(in & Min. & 0.0026 & -0.0037 & 0.0001 \\
K) & Mean & -0.0013 & -0.0015 & 0.0006 \\
RMS & Max. & 0.0030 & 0.0040 & 0.0019 \\
(in & Min. & 0.0015 & 0.0016 & 0.0015 \\
K) & Mean & 0.0022 & 0.0023 & 0.0016 \\
\hline
\end{tabular}

Table2. Statistical results compared with the integral method 
In order to further verify the accuracy of the model established in this paper, 8 sounding stations in the Qinghai-Tibet Plateau plateau area are respectively used for the test. The sounding data of 2015 was selected to evaluate was compared with the $\mathrm{K}$ value directly obtained by GPT2w model.

The analysis shows that there is a small systematicdeviation between the two, which may be due to the failure to take all the influencing factors into account when modeling transformation factors. In general, the conversion factor model calculated by the model in this paper has a high accuracy and can be used to invert PWV without the accuracy of the established model. Firstly, the observation data and meteorological data of the station were processed to obtain the high-precision $\mathrm{K}$, and then the QTm model established in this paper was used to obtain $\mathrm{K}$, which meteorological parameters.

Therefore, the atmospheric water vapor conversion coefficient $\mathrm{K}$ calculated by the QTm model established in this paper has good stability and high precision performance. It lays a good foundation for the subsequent water vapor inversion and is beneficial to the high-precision real-time water vapor calculation in the Qinghai-Tibet Plateau.
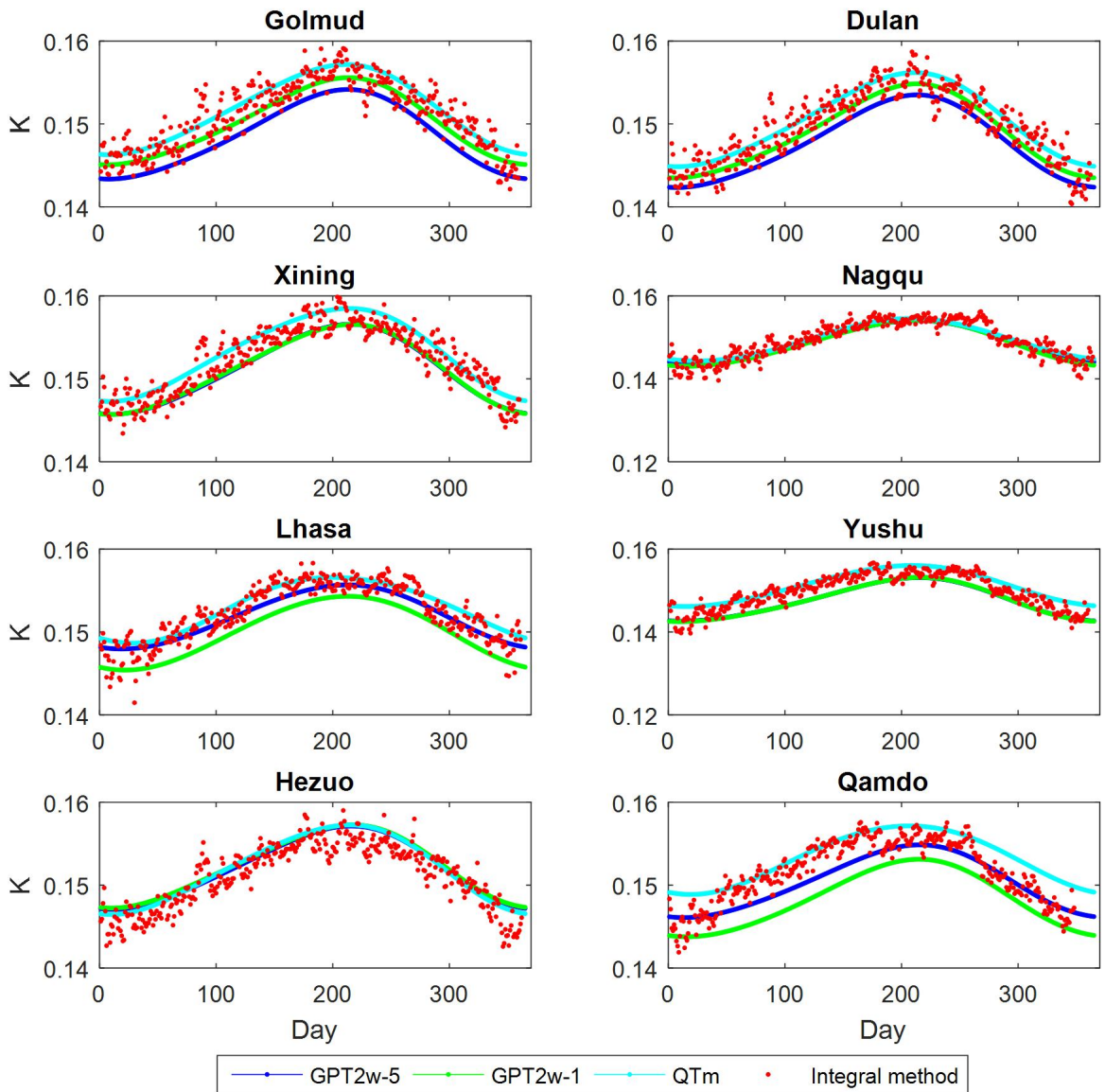

Figure6. Accuracy of three models relative to the integral algorithm 


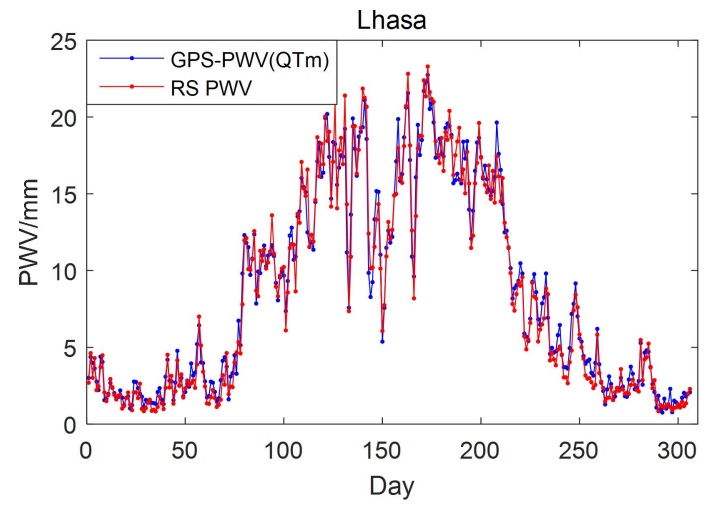

Figure7. Comparison of K-value inversion PWV with the PWV provide by radiosonde

\subsection{LHASA STATION PWV VERIFICATION ASSESSMENT}

To further verify the accuracy of the model, this paper uses the ZTD data of the 2015 Lhasa station provided by the land network and the PWV provided by the sounding station in 2015, and uses the Saastamoinen to obtain the ZHD. The ZTD minus the ZHD can be multiplied by the conversion factor K. Go to GPS-PWV. It can be seen from Fig. 7 that the PWV obtained by the K value inversion has good consistency with the PWV value provided by the sounding station.

In the evaluation of PWV, only 15 years of Lhasa station data for nearly 10 months were used.

\section{CONCLUSION}

In this paper, the atmospheric water vapor conversion coefficient of Qinghai-Tibet area is obtained by using the established weighted average temperature QTm , and the PWV of Lhasa station is inverted by the obtained $\mathrm{K}$ value. Its inversion accuracy is better than $1 \mathrm{~mm}$. This will be beneficial to the inversion of real-time water vapor in the Qinghai-Tibet Plateau. This has created conditions for better study of water vapor on the Qinghai-Tibet Plateau.

\section{Acknowledgements}

This work was sponsored by the National Natural Foundation of China (41664002; 41704027); Guangxi Natural Science Foundation of China (2018GXNSFAA29 4045; 2017GXNSFDA198016; 2017GXNSFBA198139); the "Ba Gui Scholars" program of the provincial government of Guangxi; and the Guangxi Key Laboratory of Spatial Information and Geomatics (14-045-24-10;16-380-25-01)

\section{REFERENCES}

Bevis M, Businger S, Chiswell S, Herring TA, Anthes RA,
Rocken C,Ware RH,.1994.GPS meteorology: mapping zenith wet delays onto precipitable. J Appl Meteorol 33:379-386

Bai, L., Yao, Y.B., Lei, X.X., Zhang, L.,2018.Annual and Seasonal Variation Characteristics of Surface Temperature in the Tibetan Plateau in Recent 40 Years. Journal of Geomatics.

Davis, J.L., Herring,T.A.,Shapiro, II., Rogers, AEE., Elgered, G., 1985) Geodesy by radio interferometry:effects of atmospheric modeling errors on estimates of baseline length. Radio Sci 20:1593-1607

Emardson, T.R., Derks, H.J.P.,2000.On the Relation between the WetDelay and the Intergrated Precipitable Water Vapor in Euroupean Atmosphere [ J ] .Meteorol Appl , ( 7 ): 61 - 68

He D Y, Tian H, Deng W T. Applicability analysis of three reanalysis surface temperature data over the Tibetan Plateau (in Chinese).Trans Atmos Sci, 2013: 458-465

Huang, L.K., Wu, P.T., Wang, H.Y., Liu, L.L. , 2019. Refinement Research on GPS Atmospheric Water Vapor Conversion Coefficient Model in Southwest China[J]. Journal of Geodesy and Geodynamics, 39.03:40-45.

Jiang,p.,2014. Research on 2D/3D atmospheric moisture distribution technology of ground-based GNSS sounding [D]. Wuhan university, 2014.

Qu, J.G., 2012. Calculation and Analysis of Transformation Coefficient K Value of Calculating Integrated Water Vapor[J]. 
Journal of Heilongjiang Institute of Technology,16(3);35-37

Wang, M.D., Hou, J.Z., Lei, Y. B.,2014.Classification of Tib etan lakes based on variations in seasonal lake water tempera ture. Chin Sci Bull, 59: 4847-4855

Wang, X.M, Zhang, K. F., Wu, S.Q., Fan, S.J., Cheng, Y.Y., 2016, Water vapor-weighted mean temperature and its impact on the determination of precipitable water vapor and its linear trend, J. Geophys. Res. Atmos., 121, 833-852, doi: 10.1002/2015JD024181.

Wu, P., 2012. Spatial distribution of atmospheric water vapor in summer over the Tibetan Plateau (in Chinese).Master Dissertation. Nanjing: Nanjing University of Information Science and Technology.

Yao, C.L., Luo, Z.c., Liu, L.L., Zhou, B.Y., 2015. On the Relation Between the Wet Delay and the Water Precipitable Vapor in Consideration of Topographic Relief in the Low-latitude Region of China. GEOMATICS AND INFORMATION, 40(7):907-912.

Yao Y B, Lei X X, Zhang L, et al. Analysis of precipitable water vapor and surface temperature variation over Qinghai-Tibetan Plateau from 1979 to 2014 (in Chinese). Chin Sci Bull, 2016, 61: 1462-1477, doi: $10.1360 /$ N972015-00850

Yao, Y.B., Zhu, S., Yue, S.Q., 2012.A globally applicable, season-specific model for estimating the weighted mean temperature of the atmosphere. J. Geodesy 86 (12), $1125-1135$

Yao, Y.B., Zhang, B., Xu C.Q., et al,2014.Analysis of the Global Tm-Ts Correlation and Establishment of the Latitude-Related Linear Model [ J ] .China Sci Bull , 59 : $816-824$

Yao, Y.B., GUO J.J., Zhang, B., Hu, Y.F., 2016.A Global Empirical Model of the Conversion Factor Between Zenith Wet Delay and Precipitable Water Vapor. GEOMATICS AND INFORMATION SCIENCE OF WUHAN UNIVERS, 41(1):45-51.

Yu S.J., Liu L.T., 2009.Validation and Analysis of the Water Vapor Weighted Mean Temperature from Tm-Ts
Relationship [J]. Geomatics and Information Science of Wuhan University, 34 ( 6 ): 741 -744

Zhang, Y. W., Wang, D. H., Zhai, P .M.,2013. Spatial distrib utions and seasonal variations of tropospheric water vapor co ntent over the Tibetan Plateau. J Clim, 26: 5637-5654 